\title{
Improved outcomes for very low birthweight infants: evidence from New Zealand national population based data
}

\author{
B A Darlow, A E Cust, D A Donoghue, on behalf of the Australian and New Zealand \\ Neonatal Network (ANZNN)
}

Arch Dis Child Fetal Neonatal Ed 2003;88:F23-F28

See end of article for authors' affiliations

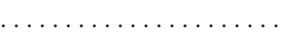

Correspondence to: Professor Darlow,

Department of Paediatrics, Christchurch School of Medicine, PO Box 4345, Christchurch, New Zealand:

brian.darlow@chmeds.ac.nz

\begin{abstract}
Objective: To compare the survival and short term morbidity of all New Zealand very low birthweight (VLBW) infants born in two epochs, 1986 and 1998-1999.

Setting: All level III and level II neonatal intensive care units (NICUs) in New Zealand.

Methods: In 1986, data were prospectively collected for a study of retinopathy of prematurity (ROP). In 1998-1999, prospective data were collected by the Australian and New Zealand Neonatal Network (ANZNN). Both cohorts included all VLBW infants born during the calendar year and admitted to a NICU. Data were collected from birth until discharge home or death.

Results: More VLBW infants were admitted for care in 1998-1999 ( $=1084,0.96 \%$ of livebirths) than in 1986 ( $n=413,0.78 \%$ of livebirths; $p<0.001)$, including a higher proportion of VLBW infants of $<1000 \mathrm{~g}$ birth weight $(38 \% \vee 32 \%$ respectively; $p<0.05)$. Survival to discharge home increased from $81.8 \%$ in 1986 to $90.3 \%$ in $1998-1999$ ( $p<0.001$ ). The 1998-1999 cohort had a higher proportion of infants born in a hospital with a level III NICU $(87 \%$ v $72 \%$ in 1986; $p<0.001)$ and receiving antenatal corticosteroids $(80 \% \vee 58 \%$ in 1986; $<<0.001)$. In 1998-1999, the incidence of several morbidities had decreased compared with 1986, including oxygen dependency at 28 days $(29 \%$ v $39 \%$ respectively; $p=0.001)$ and at 36 weeks postmenstrual age $(16 \% \vee 23 \% ; p=0.002)$, grade 1 intraventricular haemorrhage (IVH) $(8 \% \vee 24 \% ; p<0.001)$, grade $2 / 3 \mathrm{IVH}(5 \% \vee 11 \%$; $\mathrm{p}<0.001)$, and stage 3/4 ROP for infants $<1000 \mathrm{~g}(6 \%$ v 13\%; $<<0.001)$.
\end{abstract}

Conclusions: The outlook for VLBW infants in New Zealand has improved since 1986.
A dvances in both perinatal and neonatal care over the past two decades mean that increasing numbers of very preterm and very low birthweight (birth weight < 1500 g; VLBW) infants are surviving. ${ }^{1}$ In part this success has itself led to a greater willingness by obstetricians to intervene at earlier gestations with ensuing increases in the numbers of VLBW infants admitted to neonatal intensive care units (NICUs). In New Zealand, the number of VLBW infants admitted to NICUs has continued to rise in recent years despite the total number of births falling from a peak of 60000 in 1990-1991 to reach a plateau of around 57000 from $1995 .^{2}$

Given the continuing debate about the appropriateness of offering neonatal intensive care for very preterm infants, particularly those at the margins of viability, it is vital that we have a continuing audit of outcomes for these infants. In 1986, a prospective study was undertaken of all VLBW infants who were admitted to a NICU in New Zealand with the principal aim of assessing the incidence of retinopathy of prematurity (ROP).$^{3-8}$ At that time, survival to discharge home was $82 \%$. Since 1998, all hospitals with a level III NICU (regional centres with full facilities for providing neonatal intensive care; $\mathrm{n}=6$ ) and all hospitals with a level II NICU (providing special care facilities for mildly ill infants; $n=13$ ) in New Zealand have contributed data to the Australian and New Zealand Neonatal Network (ANZNN). This prospective, continuing audit of high risk infants includes all infants of birth weight $<1500$ g admitted to neonatal nurseries. The aim of this study was to compare the survival and short term morbidity of all VLBW infants born in New Zealand in two epochs, 1986 and 1998-1999.

\section{STUDY POPULATION AND METHODS}

The methods of data collection pertaining to the 1986 cohort have been described. ${ }^{36}$ Briefly, in 1986, all level III $(\mathrm{n}=5)$ and level II $(n=17)$ hospitals offering at least short term specialist newborn care prospectively collected perinatal and neonatal data, comprising 180 variables, on all infants $<1500$ $\mathrm{g}$ birth weight who were liveborn and admitted for neonatal care. In 1998-1999, all level III (now $\mathrm{n}=6$ ) and level II (now $\mathrm{n}=13$ ) hospitals in New Zealand again prospectively collected data, comprising 68 variables, for the ANZNN's audit of "high risk" infants, which includes all those with birth weight $<1500 \mathrm{~g}$. The full methods are described in the preceding paper. ${ }^{9}$ Thus the study populations comprised all infants < $1500 \mathrm{~g}$ who were live born between 1 January 1986 and 31 December 1986, and 1 January 1998 and 31 December 1999, and admitted for neonatal care at less than 28 days of age.

In both cohorts, chronic lung disease (CLD) has been reported in two ways, as supplemental oxygen requirement at 28 days of age and at 36 weeks postmenstrual age (PMA, gestational age plus chronological age). ROP has been reported using the international classification. ${ }^{10}$ In 1986 in New Zealand, it was recommended that all infants $<1500 \mathrm{~g}$ be screened for ROP by indirect ophthalmoscopy, with an initial examination at 4-6 weeks of age; but in 1998-1999, as a result of the findings in 1986, the recommendation was that

Abbreviations: ANZNN, Australian and New Zealand Neonatal Network; VLBW, very low birthweight; NICU, neonatal intensive care unit; CLD, chronic lung disease; PMA, postmenstrual age; ROP, retinopathy of prematurity; IPPV, intermittent positive pressure ventilation; CPAP, continuous positive airways pressure; IVH, intraventricular haemorrhage; GA, gestation; HMD, hyaline membrane disease. 
Table 1 Admissions and survival in the two cohorts

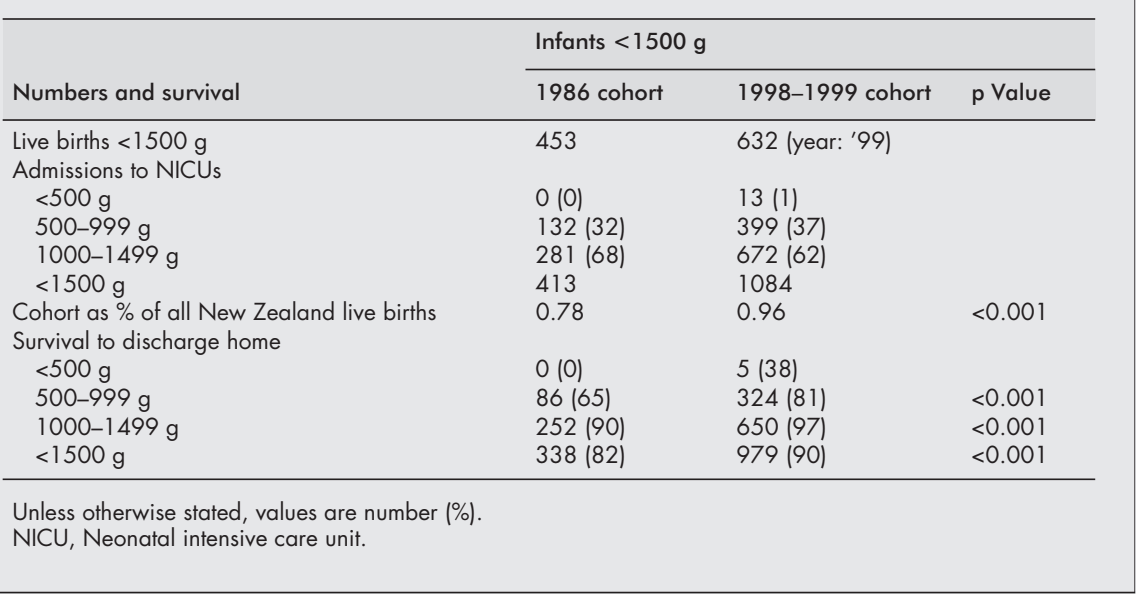

infants of either $<1250 \mathrm{~g}$ birth weight or $<31$ weeks gestation be screened. ${ }^{.1}$

In 1986, 58 (14\%) infants died before 28 days of age, and as the aim of the 1986 study was to document examination for ROP, a full dataset was not recorded prospectively for most of these infants. Hence the type and duration of assisted ventilation (defined as the use of intermittent positive pressure ventilation (IPPV) and/or continuous positive airways pressure (CPAP)) are reported here only for infants who survived to 28 days in both cohorts. Similarly, in 1986, results of cranial ultrasound scanning were only available for infants who survived beyond 1 month of age, and are hence reported for infants surviving to discharge home for both cohorts. In 1986, different classification systems were used by different NICUs but these allow data to be reported as subependymal or germinal matrix haemorrhage (grade 1), ${ }^{12}$ intraventricular haemorrhage (IVH; grades 2 and 3), and intracerebral haemorrhage (grade 4). In 1998-1999, the results of cranial ultrasound scanning were reported as the maximum grade of haemorrhage on either side by ultrasound scanning or at the postmortem examination. ${ }^{12}$ These data allow the three categories, grade 1 , grade 2 and 3 combined, and grade 4, to be reported.

In 1998-1999, there were eight $(0.7 \%)$ infants whose final date of discharge was not available from the transfer hospital, and these infants were assumed to have survived to discharge home. There were fewer than $1 \%$ of missing data for the morbidities reported in the 1998-1999 cohort, which were excluded from percentage calculations.

Specific data on national live births could be compared for the years 1986 and 1999, but were not available for 1998. ${ }^{13}$ National data on stillbirths were not directly comparable between the two cohorts because of changes in the definition of "stillbirth" in $1995 .{ }^{13}$
Statistical calculations were performed using SAS version 8. $\chi^{2}$ analysis or Fisher's exact test, where appropriate, was used for comparing proportions between the two cohorts. Statistical significance was defined at the $\mathrm{p}<0.05$ level.

\section{RESULTS}

In 1986, there were 413 infants of birth weight $<1500 \mathrm{~g}$ who were live born and admitted to a neonatal unit, accounting for $0.78 \%$ of the 52824 live births in that year (table 1). Of these infants, $338(81.8 \%)$ survived to discharge home. No infant with a birth weight $<500 \mathrm{~g}$ was admitted for care or survived. Only one infant with gestation $<24$ weeks, who survived, was admitted. Forty nine of the 75 infants (65\%) who died did so in the first week of life. An additional 40 infants were recorded as live born with a birth weight $<1500 \mathrm{~g}$ but not admitted for neonatal care. ${ }^{6}$ Including these infants (who died before admission to the nursery) would raise the proportion of VLBW infants to $0.86 \%$ of live births and reduce survival to $74.6 \%$.

In 1998-1999, 1084 infants of birth weight $<1500 \mathrm{~g}$ were live born and admitted to a neonatal unit, accounting for $0.96 \%$ of the 112402 live births in the same period (table 1). The proportion of live births in the VLBW cohort represents a $23 \%$ increase from $1986(0.78 \%$ to $0.96 \%)$. Similarly, the number of VLBW admissions represents a $31 \%$ increase during this period; the number of infants of birth weight 500$999 \mathrm{~g}$ increased by $51 \%$, and the number of infants of birth weight $1000-1499 \mathrm{~g}$ increased by $20 \%$. In 1998-1999, $90.3 \%$ of infants survived to discharge home, a $10.4 \%$ increase compared with 1986 (table 1). Survival was significantly higher in 1998-1999 for all birthweight categories, including a survival rate of $38 \%$ for the 13 infants of birth weight $<500 \mathrm{~g}$ admitted. Four infants were admitted for care who were both

Table 2 Characteristics of the two cohorts

\begin{tabular}{llll}
\hline \multirow{2}{*}{ Characteristics } & \multicolumn{2}{l}{ Infants $<1500 \mathrm{~g}$} & \\
\cline { 2 - 4 } & 1986 cohort & $1998-1999$ cohort & $\mathrm{p}$ Value \\
\hline Born in a hospital with a level III NICU & $297(72)$ & $943(87)$ & $<0.001$ \\
Born in a hospital with a level II NICU & $96(23)$ & $109(10)$ & $<0.001$ \\
Male & $213(52)$ & $542(50)$ & 0.60 \\
Infants from a multiple birth & $94(23)$ & $318(29)$ & 0.011 \\
5 minute Apgar score less than 7 & $77(19)$ & $149(14)$ & 0.025 \\
Major congenital malformation & $25(6)$ & $47(4)$ & 0.17 \\
Antenatal corticosteroids & $214(58)$ & $678(80)^{*}$ & $<0.001$ \\
\hline
\end{tabular}

Values are number (\%)

*Excludes data for two NICUs for which data were unavailable.

NICU, Neonatal intensive care unit. 
Table 3 Morbidity outcomes

\begin{tabular}{|c|c|c|c|}
\hline \multirow[b]{2}{*}{ Morbidity outcomes } & \multicolumn{3}{|c|}{ Infants $<1500 \mathrm{~g}$} \\
\hline & 1986 cohort & 1998-1999 cohort & $\mathrm{p}$ Value \\
\hline \multicolumn{4}{|l|}{ Chronic lung disease } \\
\hline \multicolumn{4}{|c|}{ Oxygen dependency at 28 days* } \\
\hline$<1000 \mathrm{~g}$ & $68(73)$ & $196(58)$ & 0.007 \\
\hline $1000-1499 \mathrm{~g}$ & $68(26)$ & $94(14)$ & $<0.001$ \\
\hline$<1500 \mathrm{~g}$ & $136(39)$ & $290(29)$ & 0.001 \\
\hline \multicolumn{4}{|c|}{ Oxygen dependency at 36 weekst } \\
\hline$<1000 \mathrm{~g}$ & $37(42)$ & $110(33)$ & 0.14 \\
\hline $1000-1499 \mathrm{~g}$ & $43(17)$ & $43(7)$ & $<0.001$ \\
\hline$<1500 \mathrm{~g}$ & $80(23)$ & $153(16)$ & 0.002 \\
\hline \multicolumn{4}{|c|}{ Retinopathy of prematurity (ROP) } \\
\hline \multicolumn{4}{|c|}{ Examined for ROP } \\
\hline$<1000 \mathrm{~g}$ & $83(97)$ & 305 (93) & 0.23 \\
\hline $1000-1499 \mathrm{~g}$ & $230(91)$ & 391 (61) & $<0.001$ \\
\hline$<1500 \mathrm{~g}$ & $313(93)$ & 696 (72) & $<0.001$ \\
\hline \multicolumn{4}{|l|}{ Stages 1 or 2 ROP§ } \\
\hline$<1000 \mathrm{~g}$ & $29(35)$ & $83(27)$ & 0.17 \\
\hline $1000-1499 \mathrm{~g}$ & $24(10)$ & $40(10)$ & 0.94 \\
\hline$<1500 \mathrm{~g}$ & 53 (17) & $123(18)$ & 0.77 \\
\hline \multicolumn{4}{|l|}{ Stages 3 or 4 ROP§ } \\
\hline$<1000 \mathrm{~g}$ & $11(13)$ & $19(6)$ & 0.03 \\
\hline $1000-1499 \mathrm{~g}$ & $1(1)$ & $2(1)$ & 1.00 \\
\hline$<1500 \mathrm{~g}$ & $12(4)$ & $21(3)$ & 0.50 \\
\hline \multicolumn{4}{|c|}{ Intraventricular haemorrhage (IVH)‡ } \\
\hline \multicolumn{4}{|c|}{ Examined for IVH } \\
\hline$<1000 \mathrm{~g}$ & $70(81)$ & 325 (99) & $<0.001$ \\
\hline $1000-1499 \mathrm{~g}$ & 179 (71) & $596(92)$ & $<0.001$ \\
\hline$<1500 \mathrm{~g}$ & 249 (74) & $921(94)$ & $<0.001$ \\
\hline \multicolumn{4}{|l|}{ Grades $1 \S$} \\
\hline$<1000 \mathrm{~g}$ & $19(27)$ & $28(9)$ & $<0.001$ \\
\hline $1000-1499 \mathrm{~g}$ & $40(22)$ & $42(7)$ & $<0.001$ \\
\hline$<1500 \mathrm{~g}$ & $59(24)$ & $70(8)$ & $<0.001$ \\
\hline \multicolumn{4}{|l|}{ Grades 2 or $3 \S$} \\
\hline$<1000 \mathrm{~g}$ & $14(20)$ & 28 (9) & 0.005 \\
\hline $1000-1499 \mathrm{~g}$ & $14(8)$ & $19(3)$ & 0.007 \\
\hline$<1500 \mathrm{~g}$ & 28 (11) & $47(5) \boldsymbol{9}$ & $<0.001$ \\
\hline \multicolumn{4}{|l|}{ Grade $4 \S$} \\
\hline$<1000 \mathrm{~g}$ & $5(7)$ & $9(3)$ & 0.07 \\
\hline $1000-1499 \mathrm{~g}$ & $4(2)$ & $14(2)$ & 1.00 \\
\hline$<1500 \mathrm{~g}$ & $9(4)$ & $23(2)$ & 0.34 \\
\hline \multicolumn{4}{|c|}{$\begin{array}{l}\text { Values are number (\%). } \\
\text { *Of infants surviving to } 28 \text { days. } \\
\text { †Of infants surviving to } 36 \text { weeks postmenstrual age. } \\
\text { †Of infants surviving to discharge. } \\
\text { §Of those examined. } \\
\text { ๆln 1998-1999, } 40 \text { (4\%) infants had grade } 2 \mathrm{IVH} \text { an }\end{array}$} \\
\hline
\end{tabular}

$<500$ g birth weight and $<24$ weeks gestation, but none survived. Of the 105 infants who died, 71 (68\%) died in the first week of life.

There was a small decrease in overall median birth weight and gestation from 1986 to 1998-1999, reflecting the increased proportion of smaller babies admitted for care. The median birth weight for infants born in 1986 was $1135 \mathrm{~g}$ (25th,75th centile: 920,1330$)$ and $1110 \mathrm{~g}(860,1338)$ in 19981999. The median gestation (GA) in 1986 was 29 weeks $(27,30)$ compared with 28 weeks $(27,30)$ in $1998-1999$.

In 1999, there were 54 infants of birth weight $<1500 \mathrm{~g}$ who were live born but not admitted for neonatal intensive care, of whom $39(72 \%)$ were $<500$ g. Including these infants would reduce overall survival in 1999 from $89.8 \%$ to $82.1 \%$, and from $90.5 \%$ to $88.2 \%$ for infants $500-1499 \mathrm{~g}$. No national data on live births were available for 1998. In 1998-1999, a higher proportion of the admitted VLBW cohort was $<1000 \mathrm{~g}$ than in $1986(38 \%$ v 32\%; $\mathrm{p}<0.05)$.

When the cohort from 1998-1999 were compared with the babies born in 1986, there was a higher proportion of infants born in a hospital with a level III NICU, more infants from a multiple birth, a lower proportion with an Apgar score of less than 7 at five minutes, and more exposed to antenatal corticosteroids (table 2). There was no difference in the rates of infants with hyaline membrane disease (HMD) (59\% in 1986 $v 58 \%$ in 1998-1999). Surfactant therapy was not available in 1986, but in 1998-1999 it was given to $90 \%$ of infants with HMD who were receiving IPPV.

In $1986,254(74 \%)$ of the infants who survived to 28 days received assisted ventilation, for a median duration $(25$ th, 75 th centiles) of 15 days $(6,33)$, compared with 866 infants $(87 \%$; $\mathrm{p}<0.001)$ for a median of 19 days $(5,43)$ in 1998-1999. Median days of assisted ventilation in 1986 for infants of birth weight $<1000 \mathrm{~g}$ was 33 days $(15,36)$, and for those of birth weight 1000-1499 g it was nine days $(3,20)$. For 1998-1999 the corresponding figures were 46 days $(28,61)$ and eight days $(3,22)$. In 1986 , only $5 \%$ of infants who received assisted ventilation were treated with CPAP only, and another $37 \%$ had a combination of CPAP and IPPV, compared with 38\% and another $60 \%$ respectively in $1998-1999$.

Table 3 describes the rates of short term morbidities in the two cohorts. The incidence of CLD was lower in 1998-1999 than in 1986, whether analysed as supplemental oxygen at 28 days or at 36 weeks. This decrease was most pronounced in the 1000-1499 g birthweight group.

The incidence of severe ROP was also reduced in 1998-1999 compared with the 1986 cohort for infants < $1000 \mathrm{~g}(6 \% \mathrm{v}$ $13 \%)$. However, in the 1000-1499 g birthweight group, there 
were fewer infants examined in 1998-1999 and no change in the rates of ROP observed. No infants were treated for ROP in 1986, as cryotherapy was not available in New Zealand until 1987. In 1998-1999, 11 infants, who were all < $1000 \mathrm{~g}$ birth weight, were treated for ROP using laser or cryotherapy. According to the screening criteria in 1998-1999, which recommended that all infants $<1250 \mathrm{~g}$ birth weight or $<31$ weeks GA be screened, $76 \%$ of eligible infants were examined (compared with $72 \%$ overall for infants $<1500 \mathrm{~g}$ birth weight). This included $93 \%$ of eligible infants $<1000 \mathrm{~g}$ birth weight, $71 \%$ in the 1000-1499 g birthweight group, and 54\% of eligible infants $\geqslant 1500 \mathrm{~g}$ birth weight.

In 1998-1999, a higher proportion of infants was examined for IVH than in 1986, accompanied by a significant reduction in the proportion with grade 1 and grades 2 or 3 IVH. In 1998-1999, periventricular leucomalacia was reported in eight infants who survived to discharge home and had an ultrasound examination at more than 20 days of age. Although not prospectively sought or routinely documented by all units in 1986, nine surviving infants were reported as having cranial ultrasound evidence of periventricular leucomalacia, suggesting a higher incidence in 1986 than in 19981999.

In 1986, surviving infants had a median (25th,75th centiles) length of stay in hospital of 67 days $(51,89)$ for infants $<1500 \mathrm{~g}$, 97 days $(75,119)$ for infants $<1000 \mathrm{~g}$, and 59 days $(48,74)$ for infants $1000-1499 \mathrm{~g}$ birth weight. In 1998-1999, the median length of stay in hospital was 62 days $(47,82)$ for infants $<1500 \mathrm{~g}$, 91 days $(72,109)$ for infants $<1000 \mathrm{~g}$, and 53 days $(41,65)$ for infants $1000-1499 \mathrm{~g}$. In 1986, the median PMA when discharged home was 39 weeks GA $(37,41)$ for infants < 1500 g, 41 weeks GA $(39,43)$ for infants < $1000 \mathrm{~g}$, and $39(37,40)$ weeks GA for infants 10001499 g. In 1998-1999, the corresponding figures were 38 weeks GA $(37,40), 39$ weeks GA $(38,41)$, and 37 weeks GA $(36,38)$.

\section{DISCUSSION}

This study has compared survival to hospital discharge and short term morbidity for all VLBW infants who were live born and admitted for neonatal intensive care, including all level III and level II NICUs, in New Zealand from two epochs, 1986 and 1998-1999. This is the first time that outcomes for a national cohort of VLBW infants from two epochs have been compared.

In this population based study, we have shown that increased numbers of infants are now being cared for, especially infants with a birth weight $<1000 \mathrm{~g}$. We have also shown that survival to discharge home has increased (from $81.8 \%$ to $90.3 \%$ ), but not to the detriment of short term morbidity. In fact, the rates of certain morbidities in survivors had decreased in 1998-1999 compared with 1986, including the requirement for supplemental oxygen at 28 days of age and at 36 weeks PMA, grade 1 and grade $2 / 3$ IVH for both $<1000 \mathrm{~g}$ and 1000-1499 g infants, and severe ROP for $<1000 \mathrm{~g}$ infants. The other morbidities that were measured in both cohorts remained unchanged in 1998-1999 compared with 1986, including stage 1 or 2 ROP, stage 3 or 4 ROP in 1000-1499 g infants, and grade $4 \mathrm{IVH}$. Although the increase in survival has been most dramatic for infants of birth weight $<1000 \mathrm{~g}$ (from $65 \%$ to $80 \%$ ), the number of extra infants in each of the two birthweight groups that would have survived in the earlier epoch if 1998-1999 survival figures had applied is similar, being an extra 19 infants of birth weight $<1000 \mathrm{~g}$ and 20 infants of birth weight 1000-1499 g. Reviews of survival after neonatal intensive care often focus on the smallest infants. However, because there are many more larger preterm infants, the impact on society of small improvements in the latter group can be just as important.

One question is whether different criteria for treatment with supplemental oxygen and screening for ROP and IVH in the two epochs contributed to the apparent decreased morbidity in 1998-1999. Monitoring of oxygen requirements beyond the first week of life was almost exclusively by oxygen saturation monitoring in 1998-1999, which only became available in New Zealand in 1989, making direct comparison with the 1986 data difficult. However, it is likely that there was more emphasis on avoiding episodes of hypoxaemia in the later period, which would tend to increase, rather than decrease, the numbers of infants receiving supplemental oxygen. As noted in the methods, the criteria for screening for ROP in 1998-1999 were derived from the 1986 data, which showed that restricting routine screening to infants $<1250 \mathrm{~g}$ or $<31$ weeks would not miss any stage 3 or 4 disease, ${ }^{3}$ therefore the significant decrease in the incidence of such disease in $<1000 \mathrm{~g}$ infants in 1998-1999 is not likely to be the result of different screening criteria. With regard to screening for IVH, it is possible that, if cranial scanning was only carried out when there was a clinical suspicion of haemorrhage in 1986, the numbers of infants with IVH as a proportion of those scanned may be higher than if scanning was routine, as it was in 1998-1999. However, if the numbers of infants with IVH in 1986 are reported as a proportion of all surviving infants, which would tend to underestimate the rate of $\mathrm{IVH}$, the rates of both grade 1 and grade $2 / 3$ IVH are still significantly higher than in 1998-1999.

It is clear that reporting outcome only for those infants admitted to neonatal units does not give a complete picture of the outcome of birth at a particular gestation or birth weight, as babies who are stillborn or who die before nursery admission are excluded. ${ }^{14}$ However, parents and caregivers still need to know the outcome for those liveborn infants who are offered intensive care. Tin and colleagues ${ }^{15}$ reported that the proportion of babies who died after the onset of labour or in the labour ward remained constant between $1983(10 \%)$ and 1991-94 (9\%). Babies who died in the labour ward also remained constant between the two epochs reported here, being $9 \%$ in both 1986 and 1999. In neither period were there any survivors with both birth weight $<500 \mathrm{~g}$ and gestation $<24$ weeks (although four such infants were admitted to NICUs in 1998-1999), suggesting that neonatologists are by and large not attempting to save smaller and smaller infants in New Zealand.

Multiple births increased significantly, which may reflect advances in obstetric care-for example, for twin to twin transfusion syndrome-and increased numbers of pregnancies following assisted reproductive techniques. The AIHW National Perinatal Statistics Unit and the Fertility Society of Australia and New Zealand report that 23.3\% of these successful pregnancies result in a premature delivery, with $6.5 \%$ of infants having a birth weight of $<1500 \mathrm{~g}$ and $20.1 \%$ being from a multiple birth. ${ }^{16}$

Perinatal and neonatal intensive care has seen many changes in the two decades covered by this study. In a landmark paper, New Zealand scientists were the first to report the use of antenatal glucocorticoids to prevent HMD, ${ }^{17}$ and this treatment has been shown conclusively to reduce mortality, HMD, and periventricular leucomalacia. ${ }^{18}$ In 1986, $58 \%$ of VLBW infants were exposed to antenatal corticosteroids, and this figure rose to $80 \%$ in 1998-1999. The increased proportion of infants receiving antenatal corticosteroids and the significantly reduced proportion of infants with a low Apgar score at five minutes in 1998-1999 suggest that improvements in obstetric care in the later period may have contributed to the improved outcome.

In the later epoch, a greater proportion of infants received assisted ventilation ( $87 \% v 74 \%)$, and for a longer duration for infants $<1000 \mathrm{~g}$. The proportion of infants who were treated with CPAP only was much greater in the second epoch $(38 \% v$ $5 \%)$, as was the proportion receiving any CPAP ( $98 \% v 42 \%)$. These data undoubtedly reflect the advent of improved "flow driver" systems for delivering CPAP and suggestions in the literature that there may be benefits from this approach. ${ }^{19}$ We are 
unable to know whether this change has contributed to the significant fall in CLD seen in 1998-1999. The benefits or otherwise of nasal CPAP, particularly early CPAP, remains an important question for future randomised controlled trials.

New Zealand already had a strongly regionalised system of neonatal intensive care in 1986, with $72 \%$ of VLBW infants admitted for neonatal care born in a hospital with a level III NICU. This model of regionalisation was further strengthened by $1998-1999$, when $87 \%$ of VLBW infants were born in a hospital with a level III NICU. Recent population based data from the state of Victoria, Australia, ${ }^{20}$ and from Sweden ${ }^{21}$ confirm earlier reports that survival of infants with birth weight $<1000 \mathrm{~g}$ or gestation $<28$ weeks is greatest if they are born in a hospital with a level III NICU.

Recent reviews of the outcome of very preterm and VLBW infants born over the past two decades have focused on the smallest infants. ${ }^{122}$ Reports comparing cohorts over time confirm increasing survival in more recent years for these infants, and most reports also show that rates of neurodevelopmental disability have been generally stable over the same time frame. ${ }^{1}$ There have been few population based studies, and no national studies, that have compared outcomes for all VLBW infants from two epochs. Robertson and colleagues ${ }^{23}$ reported population based outcomes for all infants (including stillbirths and labour ward deaths) born at 500-1250 g birth weight in the province of Alberta, Canada, in 1978-79 and 1988-89. One year survival of liveborn infants increased from $36 \%$ to $67 \%$ over this time, with no significant differences in the rates of specific childhood disabilities at 1 year $(21 \% v 15 \%$ respectively). Population based data from Victoria, Australia, have also shown increased survival at 2 years for all liveborn infants with birth weight 500-999 g born in 1991-1992 (56\%) compared with $1985-1987(38 \%),{ }^{24}$ without a significant difference in sensorineural disability at 2 years of age. O'Shea et $\mathrm{al}^{25}$ reported data for infants of 501-800 g birth weight, from two NICUs serving a 17 county region of North Carolina, between 1979 and 1994. Survival increased from 36\% in $1984-1989$ to $59 \%$ in 1989-1994, but rates of cerebral palsy ( $20 \%$ and $7 \%$ respectively), delayed mental development $(20 \%$ and $14 \%$ ), and blindness ( $0 \%$ and $4 \%$ ) were no different.

In contrast, population based data for infants $<33$ weeks GA in the Trent Health Region, United Kingdom, ${ }^{26}$ show significantly improved survival from 1992 (83\%) to 1997 (88\%), as well as from 1987 (83\%) to 1992 after adjustment for confounders, but an increase in the incidence of CLD from 1987 (11\%; 36 weeks PMA definition) to 1992 (26\%). Their rate of CLD in 1997 was 29\%, compared with $16 \%$ in this study for infants < $1500 \mathrm{~g}$ born in 1998-1999. As in our study, they noted a significantly increased number of infants admitted to a neonatal unit over time, a decrease in the median gestation and birth weight, increased use of antenatal corticosteroids, and an increasing proportion of infants receiving CPAP only as their mode of assisted ventilation. However, they found no change in median Apgar score and no difference in the proportion of infants requiring ventilation, which differs from the New Zealand situation.

The Canadian NICU Network comprised 17 level III NICUs across Canada. They reported outcomes for all VLBW infants admitted from January 1996 to October $1997 .{ }^{27}$ Survival to discharge for VLBW infants was $87 \%$ (compared with our 1998-1999 figure of 90\%), chronic oxygen dependency at 36 weeks PMA was $26 \%$ (compared with our $16 \%$ ), and severe ROP was 11\% (compared with our 3\%). The New Zealand rates may have been favourably influenced by the inclusion of all level II NICUs as well as the level III NICUs, but these data certainly suggest that the results of neonatal intensive care in New Zealand compare well with international data.

A study from Manchester, United Kingdom, ${ }^{28}$ reported increased rates of blindness from ROP in infants born at 23-25 weeks GA, from $4 \%$ in $1984-1989$ to $18 \%$ in $1990-1994$. In contrast, there have been recent reports from the United
States of falling rates of severe ROP, in some cases attributed to an increased use of antenatal steroids. ${ }^{29}{ }^{30}$ We have found no relation between exposure to antenatal steroids and both ROP of any stage or of stage 2 and higher in either the 1986 cohort or in a group of 534 VLBW infants born between 1994 and 1997 and enrolled in a randomised trial of selenium supplementation. ${ }^{31}$ Despite clear guidelines for screening for ROP and an overwhelming argument for the benefits of screening and appropriate treatment, ${ }^{32}$ only $76 \%$ of infants eligible for screening in 1998-1999 were reported to have had such an examination.

We acknowledge the limitations in this study. The 1986 study was primarily concerned with documenting ROP, and, although data were collected prospectively, a full dataset was not collected for infants who died before 28 days. Neither study collected data on infants who were stillborn or who died in the labour ward, although these data were available through national data collections in 1999, and the data have not been adjusted for severity of illness or other confounders. Furthermore, we have only reported short term morbidity, whereas long term neurodevelopmental assessment, preferably at school entry, is required to fully characterise outcome for these infants. Outcome at 7-8 years of age has been fully reported for the 1986 cohort $^{5-8}$; however, one considerable challenge for neonatal networks is to provide long term outcome data on all discharged infants, and with adequate quality controls.

In conclusion, despite significantly increased numbers of VLBW infants being admitted for care in 1998-1999 compared with 1986, including a higher proportion of extremely low birthweight infants, the rates of survival to discharge home have significantly improved. Furthermore, this has been achieved without a concomitant increase in the rates of short term morbidities in those survivors. In fact, the rates of several morbidities significantly decreased between the two epochs. We infer that these improvements may be attributable to improved regionalisation of neonatal intensive care, increased use of antenatal corticosteroids, and improvements in NICU technology and treatments such as exogenous surfactant, as well as increased experience and confidence in caring for these infants. Overall, the outlook for VLBW infants in New Zealand has greatly improved since 1986 . However, further studies are needed to determine whether these improvements in the rates of short term morbidities have translated to fewer morbidities at school age.

\section{ACKNOWLEDGEMENTS}

We would like to acknowledge the dedicated efforts of the staff within the neonatal units in New Zealand who assisted with the data collection for this study, both in 1986 and in 1998-1999. We would also like to thank L John Horwood and Nina Mogridge for their assistance with the 1986 data. We gratefully acknowledge Abbott Australasia, Abbott Laboratories New Zealand, and the level III NICUs in Australia and New Zealand, who contributed to the sponsorship of the ANZNN.

The ANZNN Advisory Committee and Executive (*) members are as follows:

\section{New Zealand}

Christchurch Women's Hospital: Nicola Austin (from 1999), Helen Liley (until 1999). Christchurch School of Medicine: Brian Darlow*. Dunedin Hospital: Roland Broadbent. Gisborne Hospital: Graeme Lear. Hastings Hospital: Jenny Corban. Hutt Hospital: Robyn Shaw, Michael Hewson (1999). Middlemore Hospital: Alan de Klerk (until 1998), Lindsay Mildenhall (from 1998). National Women's Hospital: David Knight. Nelson Hospital: Richard Mackay (until 2001), Peter McIlroy (from 2001). Palmerston North Hospital: Jeff Brown. Rotorua Hospital: Stephen Bradley. Southland Hospital: Paul Tomlinson. Taranaki Hospital: John Doran. Tauranga Hospital: Hugh Lees. Timaru Hospital: Philip Morrison. University of Auckland: Jane Harding. Waikato Hospital: David Bourchier. Wanganui Hospital: Neil MacKenzie. Wellington Women's Hospital: Vaughan Richardson. Whakatane Hospital: Chris Moyes. Whangarei Hospital: Peter Jankowitz. 


\section{Australia}

Centre for Perinatal Health Services Research, NSW: David Henderson-Smart*. Flinders Medical Centre, SA: Peter Marshall. John Hunter Hospital, NSW: Andrew Gill. King Edward Memorial Hospital for Women, WA: Ron Hagan. King George V Hospital, NSW: Nick Evans. Kirwan Hospital for Women, Qld: John Whitehall. Launceston General Hospital, Tas: Chris Bailey. Liverpool Health Service, NSW: Robert Guaran. Mater Mother's Hospital, Qld: David Tudehope. Maternity Alliance: Penny Waterson* (until 2000). Mercy Hospital for Women, Vic: Andrew Watkins. Monash Medical Centre, Vic: Kaye Bawden*, Andrew Ramsden (from 2000), Victor Yu. AIHW National Perinatal Statistics Unit: Paul Lancaster*. Nepean Hospital, NSW: Lyn Downe. Perinatal Research Centre, Qld: Paul Colditz. Princess Margaret Hospital for Children, WA: Ron Hagan, Paddy Pemberton (until 1999). Royal Children's Hospital, Vic: Neil Campbell (until 2000), Peter McDougall (from 2000). Royal Darwin Hospital, NT: Ingrid Bucens. Royal Hobart Hospital, Tas: Graham Bury. Royal Hospital for Women, NSW: Kei Lui. Royal North Shore Hospital, NSW: Jennifer Bowen. Royal Women's Hospital, Qld: David Cartwright*. Royal Women's Hospital, Vic: Colin Morley, Neil Roy. Sydney Children's Hospital, NSW: Barry Duffy. The Canberra Hospital, ACT: Graham Reynolds. The Children's Hospital at Westmead, NSW: Robert Halliday. Westmead Hospital, NSW: Marilyn Rochefort, William Tarnow-Mordi (from 2000). Women's \& Children's Hospital, SA: Ross Haslam. ANZNN Coordinator: Deborah Donoghue. ANZNN Project Officer: Anne Cust.

\section{Authors' affiliations}

B A Darlow, Department of Paediatrics, Christchurch School of Medicine, Christchurch, New Zealand

A E Cust, D A Donoghue, Centre for Perinatal Health Services Research, University of Sydney, Sydney, NSW 2006, Australia

\section{REFERENCES}

1 Hack M, Fanaroff AA. Outcomes of children of extremely low birthweight and gestational age in the 1990s. Semin Neonatol 2000:5:89-106.

2 Statistics New Zealand. Te Tari Tatau. Demographic trends 1995. http://www.stats.govt.nz/; 1996.

3 Darlow BA. Incidence of retinopathy of prematurity in New Zealand. Arch Dis Child 1988;63:1083-6.

4 Darlow BA, Horwood L. Chronic lung disease in very low birthweight infants: a prospective population-based study. J Paediatr Child Health 1992;28:301-5

5 Darlow BA, Clemett RS, Horwood L, et al. Prospective study of New Zealand infants with birth weight less than $1500 \mathrm{~g}$ and screened for retinopathy of prematurity: visual outcome at age $7-8$ years. $\mathrm{Br} J$ Ophthalmol 1997:81:935-40.

6 Darlow BA, Horwood L, Mogridge N, et al. Prospective study of New Zealand very low birthweight infants: outcome at 7-8 years. J Paediatr Child Health 1997;33:47-51

7 Darlow BA, Horwood L, Mogridge N, et al. Survival and disability at 7-8 years of age in New Zealand infants less than 28 weeks gestation. N Z Med J 1998;111:264-7.

8 Horwood LJ, Mogridge N, Darlow BA. Cognitive, educational, and behavioural outcomes at 7 to 8 years in a national very low birthweight cohort. Arch Dis Child Fetal Neonatal Ed 1998;79:F12-20.

9 Cust AE, Darlow BA, Donoghue DA. Outcomes for high risk New Zealand newborn infants in 1998-1999: a population based, national study. Arch Dis Child Fetal Neonatal Ed 2003;88:

10 International Committee for the Classification of Retinopathy of Prematurity. An international classification of retinopathy of prematurity. Pediatrics 1984;74:127-33.
11 Darlow BA, Clemett RS. Retinopathy of prematurity: screening and optimal use of the ophthalmologist's time. Aust N Z J Ophthalmol 1990; 18:41-6.

12 Papile LA, Burstein J, Burstein R, et al. Incidence and evolution of subependymal and intraventricular hemorrhage: a study of infants with birth weights less than 1,500 gm. J Pediatr 1978;92:529-34.

13 Statistics New Zealand. Te Tari Tatau. Demographic trends 2000. http://www.stats.govt.nz/; 2001

14 Evans DJ, Levene MI. Evidence of selection bias in preterm survival studies: a systematic review. Arch Dis Child Fetal Neonatal Ed 2001;84:F79-84

15 Tin W, Wariyar U, Hey E, et al. Changing prognosis for babies of less than 28 weeks' gestation in the north of England between 1983 and 1994. BM 1997;314:107-11.

16 Hurst T, Lancaster P. Assisted conception, Australia and New Zealand 1998 and 1999. Sydney: AlHW National Perinatal Statistics Unit: Assisted Conception Series No 5, 2001

17 Liggins GC, Howie RN. A controlled trial of antepartum glucocorticoid treatment for prevention of the respiratory distress syndrome in premature infants. Pediatrics 1972;50:515-25.

18 Crowley P. Prophylactic corticosteroids for preterm birth (Cochrane Review). In: The Cochrane Library. Oxford: Update Software, 2001 : issue 4.

19 De Klerk AM, De Klerk RK. Nasal continuous positive airway pressure and outcomes of preterm infants. J Paediatr Child Health 2001;37:161-7.

20 The Victorian Infant Collaborative Study Group. Changing outcome for infants of birth-weight 500-999 g born outside level 3 centres in Victoria. Aust N Z J Obstet Gynaecol 1997:37:253-7.

21 Finnstrom O, Olausson PO, Sedin G, et al. The Swedish national prospective study on extremely low birthweight (ELBW) infants. Incidence, mortality, morbidity and survival in relation to level of care. Acta Paediat 1997:86:503-11

22 Lorenz JM, Wooliever DE, Jetton JR, et al. A quantitative review of mortality and developmental disability in extremely premature newborns. Arch Pediatr Adolesc Med 1998;152:425-35.

23 Robertson CM, Hrynchyshyn GJ, Etches PC, et al. Population-based study of the incidence, complexity, and severity of neurologic disability among survivors weighing 500 through 1250 grams at birth: a comparison of two birth cohorts. Pediatrics 1992;90:750-5.

24 The Victorian Infant Collaborative Study Group. Improved outcome into the 1990s for infants weighing 500-999 g at birth. Arch Dis Child Fetal Neonatal Ed 1997;77:F91-4.

25 O'Shea T, Klinepeter K, Goldstein D, et al. Survival and developmental disability in infants with birth weights of 501 to 800 grams, born between 1979 and 1994. Pediatrics 1997;100:982-6.

26 Manktelow BN, Draper ES, Annamalai S, et al. Factors affecting the incidence of chronic lung disease of prematurity in 1987, 1992, and 1997. Arch Dis Child Fetal Neonatal Ed 2001;85:F33-5.

27 Lee SK, McMillan DD, Ohlsson A, et al. Variations in practice and outcomes in the Canadian NICU Network: 1996-1997. Pediatrics 2000;106:1070-9

28 Emsley HC, Wardle SP, Sims DG, et al. Increased survival and deteriorating developmental outcome in 23 to 25 week old gestation infants, 1990-4 compared with 1984-9. Arch Dis Child Fetal Neonatal Ed 1998;78:F99-104

29 Higgins RD, Mendelsohn AL, DeFeo M, et al. Antenatal dexamethasone and decreased severity of retinopathy of prematurity. Arch Ophthalmol $1998 ; 116: 601-5$

30 Blair BM, O'Halloran H S, Pauly TH, et al. Decreased incidence of retinopathy of prematurity, 1995-1997. J AAPOS 2001;5:118-22.

31 Darlow B, Graham P, Horwood J, Mogridge N, Clemett R. Do antenatal steroids reduce the incidence of severe retinopathy of prematurity? Proceedings of the 3rd Annual Congress of the Perinatal Society of Australia and New Zealand; March 1999; Melbourne, Australia. Melbourne: Perinatal Society of Australia and New Zealand, 1999:148.

32 Clemett R, Darlow B. Results of screening low-birth-weight infants for retinopathy of prematurity. Curr Opin Ophthalmol 1999;10:155-63. 